Edgar Bernad-Mechó*

Universitat Jaume I, Spain

ebernad@uji.es

\title{
MODAL DENSITY IN STRUCTURING SEGMENTS CONTAINING ORGANIZATIONAL METADISCOURSE VERSUS CONTENT SEQUENCES
}

\section{Abstract}

Organizational metadiscourse in lectures helps to facilitate comprehension and is frequently found in structuring segments placed in between content sequences. In contrast, content sequences are those parts of the discourse which carry the main ideas to be developed in the lecture. Although there is ample literature that explores the use of metadiscourse in lectures, to the best of our knowledge, no previous research has compared both parts of the monological classroom discourse with regard to the semiotic resources used by lecturers. Thus, this paper aims to compare and contrast structuring segments and content sequences with a focus on the use of multimodal resources. In order to do so, six structuring segments with a high number of organizational metadiscourse instances and six content sequences from six different lectures have been selected. These lectures are face-to-face recorded sessions that belong to Humanities courses at Yale University OpenCourseWare. Through the observation of short clips and multimodal transcriptions using the software Multimodal Analysis Video, I present quantitative and qualitative data that provides evidence that organizational metadiscourse is most often co-expressed with non-verbal resources in structuring segments, which contributes to emphasizing the connections across the contents, and to engaging the audience. In other words, structuring segments appear to be more modally dense than content sequences.

\section{Key words}

multimodality, metadiscourse, structuring segments, content sequences, lectures.

* Corresponding address: Edgar Bernad-Mechó, Departament d'Estudis Anglesos, Av. Sos Baynat s/n, E12071, Spain. 


\section{INTRODUCTION}

This article compares two main sections within monological academic lectures structuring segments and content sequences - to describe their modal density. Before looking at these concepts, it is necessary to define the terms lecture and lecturer. On the one hand, lectures constitute a classroom genre (Fortanet-Gómez, 2005) in which a lecturer delivers new information to students in a lecture room, about a specific topic, and generally through spoken interaction (Malavska, 2016). Lecturers, in turn, possess a degree of expertise on the given topic and are involved in the lecture providing the audience with information as well as opinions (Chafe, 1992; Malavska, 2016; Thompson, 1994).

Having said that, "lectures are not homogeneous" (Fortanet-Gómez \& Bellés Fortuño, 2005: 162). A basic distinction may be established between two main types of lectures: monological (or non-interactive) and dialogical (or interactive) lectures. Moreover, a new element has been increasingly introduced to this complex scene: online lectures. It is worth pointing out that although the lectures used in the analysis in this article have been extracted from an online platform, they consist of traditional face-to-face sessions that were recorded and uploaded online with no editing process. Therefore, the study here presented is based on traditional monological lectures as defined by Waugh and Waugh (1999: 35-36):

"A lecture is a teaching method where the lecturer talks, acts, persuades, cajoles;

in fact, has perfect freedom to do whatever is desired, except to ask students to answer questions. The students do not discuss in the lecture the information conveyed, or question the lecturer verbally."

This type of lectures poses several advantages: they are practical for large classes and for extensive contents, and they may be updated and re-used (Crawford Camiciottoli, 2007).

Lectures have been thoroughly researched in the past decades, with a special focus on language comprehension (Flowerdew, 1994; Lynch, 1994) or the interpersonal factors influencing the learning process (MacDonald, Badger, \& White, 2000; Thompson, 1992). Most of these studies, however, focus only on one mode of communication, i.e. the linguistic mode. In contrast, an interest has been recently developed by many researchers into the study of lectures beyond a linguistic perspective, considering also non-verbal embodied and disembodied modes as elements to convey meaning. Thus, with the rise of multimodal approaches, there has been a paradigm shift in the research of lectures to explore, among others, the combination of modes to engage the audience (Bernad-Mechó \& Fortanet-Gómez, 2019; Crawford Camiciottoli, 2016), the use of visuals (Bruti, 2015), multimedia learning (Tan, O'Halloran, \& Wignell, 2016), etc. These perspectives offer a more extensive description of the genre of lectures as they understand that communication also occurs beyond the linguistic message and look at what specific combinations of modes come into play in the conveyance of meaning. 
Crawford Camiciottoli (2015), for instance, analyzes five Humanities lectures with a focus on how explanations are carried out. She explores the co-occurrence of prosodic stress, gaze, and gestures with verbal explanations. At a linguistic level, Crawford Camiciottoli concludes that Humanities lecturers seem to resort to complex explanatory strategies over simpler ones like exemplification. Moreover, the multimodal analysis carried out in this study reveals how explanations commonly co-occur with gaze towards the audience as well as gestures and prosodic emphasis. In this sense, this author argues that this particular combination of modes in explanatory sections reinforces comprehension and carries out the function of engaging the audience in the learning process.

Similarly, in Bernad-Mechó and Fortanet-Gómez (2019), lecturers' engagement strategies are analyzed as specific combinations of modes in organizational messages. A series of sections within a set of lectures are identified in which metadiscourse is employed to introduce topics, review and/or preview information, etc. These sections proved to be multimodally rich and the analysis demonstrates that lecturers go an extra step to make sure that this organizational message reaches the audience by combining the linguistic words with other non-verbal modes (gaze, gestures, postures shifts, etc.). Furthermore, this article shows the relationship between lecturing styles and specific combinations of modes. These specific combinations of modes are commonly referred to as multimodal ensembles, i.e. the processes in which different modes are assembled and organized together (Kress, 2010).

It is precisely the study of lecturing styles one of the variables that influences the use of specific combinations of modes (Bernad-Mechó, 2018). In this sense, Dudley-Evans (1994: 148) presents a classification of lecturing styles that establishes three main types of lectures depending on the lecturers' use of notes:

a) Reading style: It comprises lectures "in which lecturers either read the lecture or deliver it as if they were reading it".

b) Conversational style: It refers to those lectures "in which lecturers deliver the lecture from notes and in a relatively informal style with a certain amount of interaction with students".

c) Rhetorical style: It encompasses sessions "in which lecturers give a performance with jokes and digressions".

This taxonomy is broader than Waugh and Waugh's (1999) definition of lectures as it leaves an open door to including certain amounts of dialogic interaction, particularly in conversational and rhetorical styles. Following these concepts, differences across lectures are shown not only as far as the use of notes is concerned, but also from a multimodal point of view. In fact, lecturers seem to turn to different sets of non-verbal modes when trying to engage the audience depending on their lecturing style. For instance, a reading style lecturer whose gaze is mostly 
focused on their notes might resort to shifting their gaze towards the audience when trying to engage them (Bernad-Mechó \& Fortanet-Gómez, 2019).

As stated above, two main types of sections are identified in lectures for the purposes of this article: content sequences and structuring segments. While content sequences refer to those moments within the lecture where curricular content is advanced, structuring segments are organizational parts within lectures in which lecturers make comments on the content (for instance, to preview or review some content information, introduce new topics, conclude topics, etc.). In these sections, content is not advanced but reflected upon so as to ease comprehension on both the content itself and the structures of the lectures and courses.

In order to identify structuring segments within the lecture, organizational metadiscourse may be used as a reference. To do so, I make use of Ädel's (2010) taxonomy for metadiscourse, as it is partially based on spoken academic lectures. She suggests two broad categories of metadiscourse: metatext, which is divided into metalinguistic comments, discourse organization and speech act labels; and audience interaction, consisting of references to the audience. The category "discourse organization" encompasses all those metadiscursive elements that contribute to the structuring of lectures: introducing topic, delimiting topic, adding to topic, concluding topic, making asides, enumerating, endophoric marking, previewing, reviewing, and contextualizing. Thus, by identifying sections within the lectures with a high concentration of these instances, structuring segments may be disclosed.

Finally, this article explores the modal density of specific sections within lectures. Modal density is a term that has been traditionally used within multimodal theories in relation to the levels of attention/awareness that social actors show when conducting actions (Norris, 2004). In other words, an action is more or less modally dense when either many modes co-occur within any one action or when a specific mode takes a more relevant role in the performance of such action. In this paper, however, the former scenario is favored: a section (either structuring segments or content sequences) will be more modally dense when the message is conveyed more complexly as more modes co-occur in a given multimodal ensemble.

All in all, the present study expands on previous research on multimodality in academic lectures by looking at the modal density of content sequences and structuring segments. I argue that structuring segments are more modally dense since lecturers, regardless of their lecturing style, try to emphasize the structure and organization of the classroom through a complex multiplicity of modes.

\section{METHODOLOGY}

\subsection{The dataset}

In order to explore the modal density in both structuring segments and content sequences, a dataset of six university lectures in Humanities was compiled from 
which twelve fragments (six structuring segments and six content sequences) were extracted. The dataset comes from a larger study in which 152 lectures were explored (Bernad-Mechó, 2018). The lectures for this study were all extracted from the OpenCourseWare (OCW) offered at Yale University's website. ${ }^{1}$ Yale University offers online access to 42 full university courses covering a large range of fields of study, including Humanities, social and natural sciences. Still, Yale University's OCW is not designed for online courses, but consists of a compilation of face-to-face traditional lectures that were recorded at Yale University between years 2006 and 2011 and then uploaded to the website to make them accessible to the public. In this respect, no apparent difference can be established between a self-recorded lecture and the online lectures provided in Yale University's OCW.

The fragments selected for the present study were specifically chosen to account for three variables: on the one hand, the main objective of this study is to compare the use of multimodal resources and, therefore, the modal density, in two typical moves in lectures (structuring segments and content sequences). On the other hand, the fragments were picked to equally represent each of the lecturing styles (conversational, rhetorical and reading), which allows for the exploration of any possible differences in the use of semiotic resources across these styles. Finally, the dataset aims to be as homogeneous as possible in terms of content and structure; consequently, only lectures from Humanities were selected. Thus, the lectures used in this paper were extracted from the following courses:

Course 1 (C1) - African American History, from Emancipation to the Present

Course 2 (C2) - The American Revolution

Course 3 (C3) - Philosophy: Death

Course 4 (C4) - The American Novel since 1945

Course 5 (C5) - Epidemics in Western Society since 1600

Course 6 (C6) - Cervantes' Don Quixote

Out of these, $\mathrm{C} 1$ and $\mathrm{C} 2$ are taught by conversational style lecturers, C3 and C4 by rhetorical style lecturers, and C5 and C6 by reading style lecturers. Two clips were selected from each lecture. First, six excerpts were chosen considering those fragments containing abundant organizational metadiscourse; in other words, structuring segments were identified and one of them was selected in each of the lectures. The introductions to the lectures were prioritized when selecting the fragments for the multimodal analysis due to their organizational traits and the high amount of organizational metadiscourse; however, the introductions in courses 3 and 4 are far too short, and therefore, structuring segments taking place later in the development of the lectures were selected. As stated in the previous section, organizational metadiscourse was identified following Ädel's (2010) taxonomy.

\footnotetext{
1 https://oyc.yale.edu/ Last accessed July 12, 2021. Licensed under Creative Commons AttributionNoncommercial-Share Alike 3.0 license.
} 
Still, only the four more frequent types of organizational metadiscourse, i.e. introducing topic, previewing, reviewing, and contextualizing (Bernad-Mechó, 2018), were considered for the analysis, as the presence of other types of organizational metadiscourse is minimal. These segments were chosen taking into account the first metadiscursive instance in the fragment as the starting point, and the end of the last metadiscursive utterance marking the completion of the segment.

Furthermore, six excerpts containing the development of content information were also selected; one per lecture. In order to choose these fragments, short explanations containing no metadiscourse instances were identified in the bodies of the lectures, i.e. the sections after the introductions and before the conclusions. Out of these, random examples were picked in which the logical development of a singletopic explanation was separated by long pauses. Consequently, the fragments show distinct runtimes; however, this is not relevant for the analysis of the semiotic resources as the results will be shown in percentages over the total duration of the clip, regardless of their duration.

\begin{tabular}{|c|c|c|c|c|c|}
\hline CoDE & TYPE & No. WORDS & DURATION & $\begin{array}{c}\text { EXTRACTED } \\
\text { FROM }\end{array}$ & $\begin{array}{l}\text { LECTURING } \\
\text { STYLE }\end{array}$ \\
\hline C1_L13_SS & $\begin{array}{c}\text { Structuring } \\
\text { segment }\end{array}$ & 377 & $2^{\prime} 48^{\prime \prime}$ & $\begin{array}{c}06: 52: 18 \text { to } \\
09: 40: 12\end{array}$ & Conversational \\
\hline C2_L13_SS & $\begin{array}{c}\text { Structuring } \\
\text { segment }\end{array}$ & 564 & 3'39" & $\begin{array}{c}00: 01: 00 \text { to } \\
03: 39: 23\end{array}$ & Conversational \\
\hline C3_L15_SS & $\begin{array}{c}\text { Structuring } \\
\text { segment }\end{array}$ & 260 & $2^{\prime} 5^{\prime \prime}$ & $\begin{array}{c}14: 47: 29 \text { to } \\
16: 52: 29\end{array}$ & Rhetorical \\
\hline C4_L13_SS & $\begin{array}{c}\text { Structuring } \\
\text { segment }\end{array}$ & 235 & 1'53" & $\begin{array}{c}\text { 07:16:01 to } \\
\text { 09:09:01 }\end{array}$ & Rhetorical \\
\hline C5_L15_SS & $\begin{array}{c}\text { Structuring } \\
\text { segment }\end{array}$ & 239 & 2'13" & $\begin{array}{c}00: 01: 00 \text { to } \\
02: 14: 00\end{array}$ & Reading \\
\hline C6_L15_SS & $\begin{array}{c}\text { Structuring } \\
\text { segment }\end{array}$ & 362 & 3'24" & $\begin{array}{c}00: 01: 00 \text { to } \\
03: 24: 29\end{array}$ & Reading \\
\hline C1_L13_CS & Content sequence & 354 & 2'36" & $\begin{array}{c}34: 54: 27 \text { to } \\
37: 30: 18\end{array}$ & Conversational \\
\hline C2_L13_CS & Content sequence & 285 & $2^{\prime}$ & $\begin{array}{c}21: 55: 21 \text { to } \\
23: 55: 17\end{array}$ & Conversational \\
\hline C3_L15_CS & Content sequence & 290 & $2^{\prime} 6^{\prime \prime}$ & $\begin{array}{c}30: 39: 29 \text { to } \\
32: 45: 25\end{array}$ & Rhetorical \\
\hline C4_L13_CS & Content sequence & 264 & $2^{\prime}$ & $\begin{array}{c}26: 58: 29 \text { to } \\
28: 58: 24\end{array}$ & Rhetorical \\
\hline C5_L15_CS & Content sequence & 217 & 2' 13" & $\begin{array}{c}34: 28: 00 \text { to } \\
36: 40: 29\end{array}$ & Reading \\
\hline C6_L15_CS & Content sequence & 208 & 1'38" & $\begin{array}{c}34: 44: 00 \text { to } \\
36: 21: 24\end{array}$ & Reading \\
\hline
\end{tabular}

Table 1. Description of the dataset of structuring segments and content sequences

At this point, it is important to remark that fine-grained multimodal analyses are commonly extensive and time-consuming. For the present study, a multimodal 
annotation software application - Multimodal Analysis-Video (MMA-Video) (O'Halloran et al., 2012) - was used for the identification of verbal and non-verbal cues conveying meaning in organizational and content instances. Consequently, the twelve excerpts selected from the lectures were imported into the software for analysis. Table 1 above describes the fragments chosen for the multimodal analyses.

\subsection{Annotation and analysis}

Once the fragments were selected, they were imported into the tool MMA-Video for their annotation and analysis. Following previous explorations of the use of semiotic resources in lectures (Bernad-Mechó, 2018; Bernad-Mechó \& Fortanet-Gómez, 2019; Crawford Camiciottoli, 2015, 2016; Tan et al., 2016), the modes that were taken into account in the analysis were: the verbal mode (exploration of metadiscourse vs content language, as well as the percentage of pauses over the total duration of the clips), the use of gestures - iconic, metaphoric, deictic or beats (McNeill, 1992), gaze direction, head movements - iconic or novel (Norris, 2004), posture, proxemics, and facial expressions. The mode of paralanguage, although undoubtedly relevant in multimodal analysis, may become quite subjective when trying to quantify it (Bernad-Mechó, 2018) and, therefore, it was excluded from the analyses. Figure 1 below summarizes the analytical framework employed for the present study.

As stated above, the annotation of these modes was conducted using MMAVideo. MMA-Video's interface (see Figure 2) is made up of four broad sections: a video window where the clips can be played [1]; a box for verbal transcriptions [2]; a set of three boxes where system choices can be singled out [3], i.e. the analyst can describe each of the semiotic resources used by the lecturer; and a list of strips where choices are annotated in time [4]. Three strips are provided by default by the software in this section: the film strip, which displays snapshots extracted from the video clip; the sound strip, which displays a waveform of the audio in the clip; and the dialog strip, where the verbal transcription can be inserted and which is displayed in box [2]. The rest of the strips are created manually with the aim of annotating all relevant semiotic resources employed in the lecture fragments. 


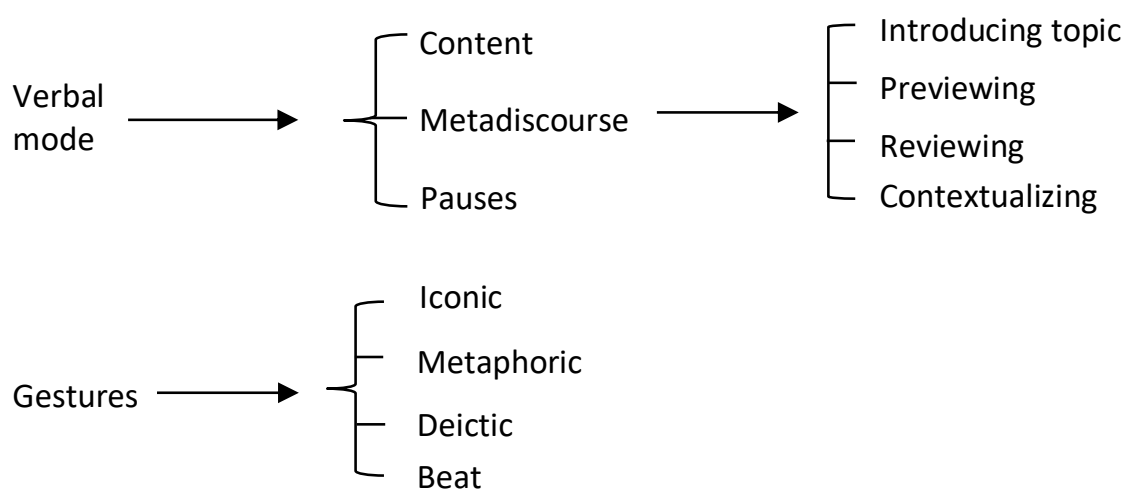

Gaze

direction $\longrightarrow$ Towards notes/Towards audience/Towards book/...

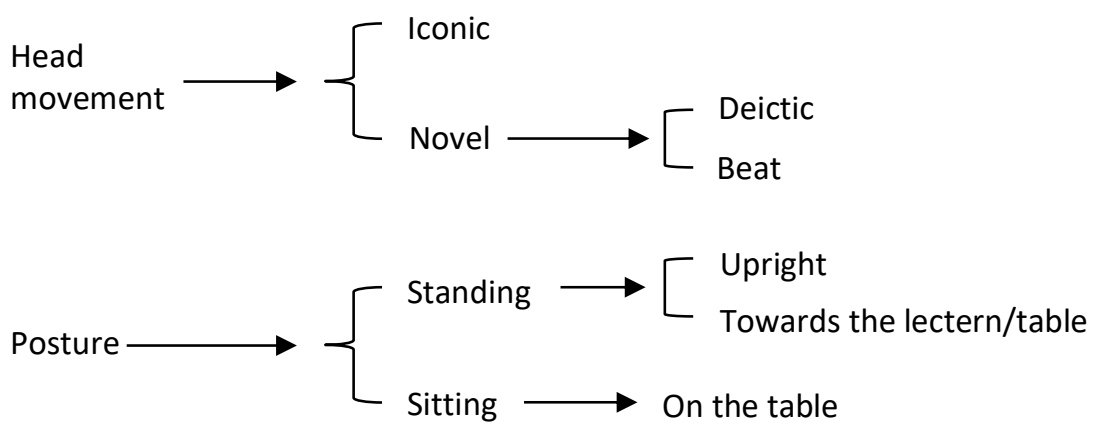

Proxemics $\longrightarrow$ Lectern/Table/On table/To board/In front of the audience/...

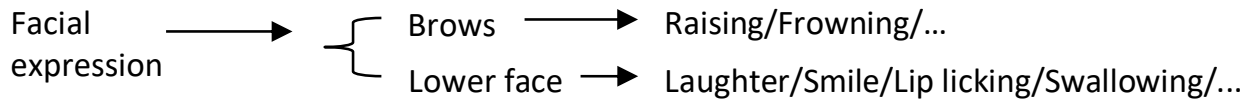

Figure 1. Framework for the multimodal annotation

Once all occurring instances for each of the modes were annotated in the program for each of the fragments, a quantitative analysis was carried out using the tool State Machine included in software. This tool is able to provide percentages of use over the total clip duration for each of the semiotic resources under study. Furthermore, State Machine is also able to provide information on what particular combinations of modes are chosen in any single instance (multimodal ensembles). This qualitative analysis offers information on the lecturers' choices both when structuring and organizing the lecture and when purely teaching content. All in all, 
the microanalysis of the modes using MMA-Video offers a comprehensive review on the use of multimodal resources both in structuring segments and in content sequences, and both from a quantitative and a qualitative perspective.

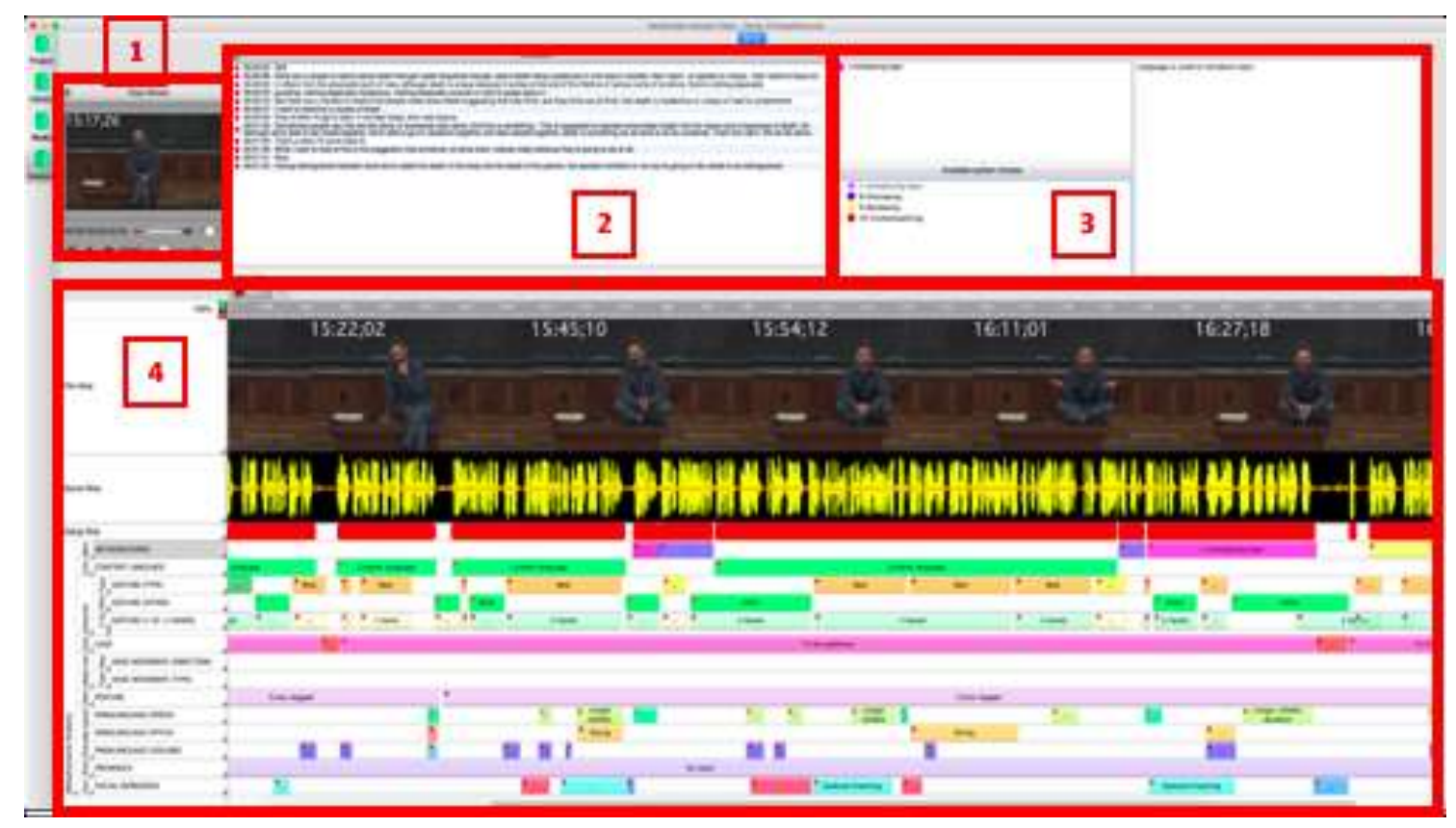

Figure 2. MMA-Video's interface

Thus, once the percentages of use were obtained and the multimodal ensembles explored, the data were compared. The following section summarizes the results obtained with MMA-Video for each of the communicative events studied, and discusses the most relevant findings.

\section{RESULTS AND DISCUSSION}

The results section of this paper has been structured in two main parts. Firstly, we explore the quantitative data shown in the analysis of structuring segments and content sequences in MMA-Video. Then, the second section shows qualitative results arising from the comparison of representative multimodal ensembles occurring in these communicative events.

\subsection{Modal density: Comparing the quantitative use of semiotic resources}

Table 2 below describes the quantitative results obtained when exploring each of the semiotic resources employed by each of the lecturers individually in structuring 
segments. The figures are shown in terms of percentages over the total duration of the video clips; thus, for example, the figure 23.21 in Gestures $>$ Gesture type $>$ Beat for the lecturer in C1 indicates that this lecturer performs beats during $23.21 \%$ of the time of the clip, and so on and so forth. In short, the recurrent semiotic resources that seem to play an important role in the structuring segments are the verbal mode, gestures, gaze, posture and proxemics.

\begin{tabular}{|c|c|c|c|c|c|c|c|c|}
\hline \multirow{2}{*}{ System } & \multirow{2}{*}{\multicolumn{2}{|c|}{ System choices }} & \multicolumn{6}{|c|}{ System utilization (\% over total duration) } \\
\hline & & & C1 & C2 & C3 & C4 & C5 & C6 \\
\hline \multirow{6}{*}{ Verbal mode } & \multirow{5}{*}{ Metadiscourse } & 1- Introducing topic & 3.57 & 4.55 & 23.39 & 15.93 & 18.80 & 9.80 \\
\hline & & 8- Previewing & 13.69 & 26.82 & 4.84 & 19.47 & 8.27 & 8.33 \\
\hline & & 9- Reviewing & 16.07 & 22.27 & 9.68 & 6.19 & - & 34.80 \\
\hline & & 10- Contextualizing & - & 3.18 & - & - & 1.50 & - \\
\hline & & TOTAL & 33.33 & 56.82 & 37.91 & 41.59 & 28.57 & 52.93 \\
\hline & \multicolumn{2}{|l|}{ Pauses } & 24.40 & 7.27 & 9.68 & 13.27 & 15.04 & 21.08 \\
\hline \multirow{5}{*}{ Gestures } & \multicolumn{2}{|l|}{ Total gesturing } & 35.11 & 63.76 & 50.40 & 56.63 & 0.75 & 7.89 \\
\hline & \multirow{4}{*}{ Gesture type } & Iconic & 2.38 & - & - & 4.42 & 0.75 & - \\
\hline & & Metaphoric & 2.38 & 6.88 & 1.60 & 4.42 & - & 0.99 \\
\hline & & Deictic & 7.14 & 4.13 & 4.80 & - & - & 0.99 \\
\hline & & Beat & 23.21 & 52.75 & 44 & 47.79 & - & 5.91 \\
\hline \multirow{4}{*}{$\begin{array}{l}\text { Gaze } \\
\text { direction }\end{array}$} & \multicolumn{2}{|c|}{ Towards the audience } & 43.20 & 61.19 & 95.55 & 95.61 & 45.62 & 39.22 \\
\hline & \multicolumn{2}{|c|}{ Towards the notes } & 55.62 & 37.44 & - & 3.51 & 52.13 & 58.82 \\
\hline & \multicolumn{2}{|c|}{ Towards the book } & - & - & - & - & - & - \\
\hline & \multicolumn{2}{|l|}{ Other } & 1.18 & 1.37 & 4.45 & 0.88 & 2.25 & 1.96 \\
\hline \multirow{3}{*}{$\begin{array}{l}\text { Head } \\
\text { movement }\end{array}$} & \multicolumn{2}{|l|}{ Iconic } & 0.60 & - & - & - & - & - \\
\hline & & Deictic & - & - & - & - & - & - \\
\hline & Novel & Beat & - & 9.10 & 0.80 & - & - & 0.49 \\
\hline \multirow{6}{*}{ Posture } & \multirow{4}{*}{ Standing } & Upright & 69.86 & 82.65 & - & 97 & 50 & 34.31 \\
\hline & & Towards the lectern & 30.14 & 17.35 & - & - & 50 & 65.69 \\
\hline & & Towards the table & - & - & - & 3 & - & - \\
\hline & & Of which, swaying & 50.60 & 16.44 & - & - & 74.44 & 18.14 \\
\hline & \multirow{2}{*}{$\begin{array}{l}\text { Sitting on the } \\
\text { table }\end{array}$} & Cross-legged & - & - & 84 & - & - & - \\
\hline & & Stretched & - & - & 16 & - & - & - \\
\hline \multirow{4}{*}{ Proxemics } & \multicolumn{2}{|c|}{ Behind the lectern } & 100 & 100 & - & - & 100 & 100 \\
\hline & \multicolumn{2}{|l|}{ On the table } & - & - & 100 & - & - & - \\
\hline & \multicolumn{2}{|l|}{ By the table } & - & - & - & 4.39 & - & - \\
\hline & \multicolumn{2}{|c|}{ In front of the audience } & - & - & - & 95.61 & - & - \\
\hline \multirow{5}{*}{$\begin{array}{l}\text { Facial } \\
\text { expression }\end{array}$} & \multirow{2}{*}{ Brows } & Eyebrow raising & 2.38 & 4.40 & 8 & 4.41 & 1.50 & 2.94 \\
\hline & & Frowning & - & - & 15.20 & - & - & 4.41 \\
\hline & \multirow{3}{*}{ Lower face } & Smiling & - & 2.38 & - & - & - & - \\
\hline & & Lip licking & 2.38 & 1.12 & 0.80 & 0.88 & 7.52 & - \\
\hline & & Swallowing & 2.38 & 2.38 & 3.20 & 0.88 & - & 0.98 \\
\hline
\end{tabular}

Table 2. Percentages of use of modes in structuring segments

An interesting element within the verbal mode in structuring segments, as expected, is the elevated frequency of organizational metadiscourse, ranging from $28.57 \%$ of the total duration of the clip (C5) to $56.82 \%$ (C2). The amount of metadiscourse in each of the excerpts has to do with the metadiscursive act carried 
out by each of the lecturers (introducing topic, reviewing information, etc.) and the particular contents of such act. Furthermore, within the verbal mode, some distinctive traits may start to appear across lecturing styles when looking, for instance, at the use of pauses. The percentage of pauses describes the amount of time in which lecturers are silent. In general terms, pauses seem to be more frequent in reading style lecturers (15.04\% in C5 and $21.08 \%$ in C6), although they are also employed by conversational style lecturers, who depend on their notes for the organization of the contents $(\mathrm{C} 1=24.40 \%)$. Finally, although silences in rhetorical style lecturers are not common, these lecturers seem to perform longer pauses when changing ideas in line with previous research (Bernad-Mechó \& FortanetGómez, 2019). We argue that these pauses are the result of a process of selforganization of thoughts in which lecturers move from one idea to the other. Having fewer verbal metadiscursive markers in their speech, these pauses might help to mark the distinction between ideas.

As for gestures, these are one of the most common semiotic resources utilized while speaking in structuring segments. On the whole, beats are the most common type of gestures throughout the data. These gestures lack semantic content (Andric \& Small, 2012), often accompany speech, and are used to mark the rhythm of the interaction or to emphasize certain parts of the discourse (Leonard \& Cummins, 2011). The use of metaphoric and deictic gestures, although not as common, also receives a degree of attention in general terms, while iconic gestures are the less used. When looking at the lecturing styles, two main trends seem to arise: on the one hand, conversational and rhetorical style lecturers make a fair use of gestures (ranging from 35.11\% to 63.76\%); on the other hand, reading style lecturers show the lowest figures in terms of gesture use $(0.75 \%$ for C5, and $7.89 \%$ for C6). In this regard, reading style lecturers mostly focus on their notes and their hands are mainly placed either on the notes or on the lectern. Consequently, the use of gestures is limited for this type of lecturers. In this line, those gestures which are present seem to be more frequent in spontaneously-driven comments that drag reading style lecturers off their notes into a more conversational style.

In the case of gaze, this semiotic resource appears to be an indicator of the foci of the lecturers (whether they are focused on their notes or on the audience) and serves as an engager tool to bring the audience into the lecturing process (BernadMechó \& Fortanet-Gómez, 2019). This seems to be particularly relevant when signaling the direction and organization of the lecture through organizational metadiscourse, i.e. in structuring segments. Thus, the more lecturers depend on notes, the more they turn their gaze towards them. On the one hand, when lecturers produce spontaneous comments their gaze is mostly directed towards the audience as they are providing information that has not been planned for and is not in their notes. In the dataset, differences across lecturing styles are easily identified in the use of gaze in structuring segments. Rhetorical style lecturers gaze at the audience almost throughout the fragments. In contrast, reading style lecturers look both at the audience, and particularly, towards the notes (52.13\% in C5 and 58.82\% in C6). 
Finally, conversational style lecturers also share their gaze between the audience and the notes. However, the amount of time directed to the notes is dissimilar in these lecturers (55.62\% in $\mathrm{C} 1$ and $37.44 \%$ in $\mathrm{C} 2$ ). This seems to indicate a higher relevance of notes for the lecturer in C1 during structuring segments, as this lecturer makes constant pauses to check his notes before introducing new information.

The analysis of head movement reveals the fact that its use is rather limited if compared to other semiotic resources. In fact, only the lecturer in C2 makes a frequent use of this semiotic resource as she produces head beats during $9.10 \%$ of the time. This seems to be an individual trait of this lecturer as no other relevant uses have been found in the data. According to Norris (2004), the more head movements, the stronger the message is. Thus, the head movements identified in $\mathrm{C} 2$ might serve as intensifiers of the message.

As for posture, the ways in which lecturers position their bodies provide input on how the lecturers relate to their audience and their environment. Differences across lecturing styles in the use of posture are evident. On the one hand, rhetorical style lecturers show "alternative" strategies to lecturing position, as opposed to the traditional behind-the-lectern style. Particularly, the lecturer in C3 sits on his table during his lectures, and the lecturer in $\mathrm{C} 4$ stands in front of the audience. In both cases, their postures face the audience at all times, thus engaging the audience in their discourse. The rest of the lecturers, both conversational and reading style lecturers, stand behind their lecterns and alternate an upright position facing the audience and a leaned position towards the lectern that indicates that the focus is on the notes. The use of upright positions is more frequent in conversational style lecturers (69.86\% for $\mathrm{C} 1$ and $82.65 \%$ for $\mathrm{C} 2$ ) than in reading style lecturers who lean towards the lectern more frequently (50\% in C5 and $65.69 \%$ in C6). Finally, a slight swaying movement has been identified in both conversational and reading style lecturers, which may be used as a rhythm marker to accompany speech.

When looking at proxemics and the use the lecturers make of the classroom spaces, two trends can be easily identified. On the one hand, conversational and reading style lecturers make little use of the classroom space. Basically, these lecturers stand behind the podium and they alternate facing the audience and their notes. Rhetorical style lectures, on the other hand, stand closer to the audience, which fosters audience's engagement in the lecture.

Lastly, the use of facial expression as a semiotic resource is generally limited and does not seem to be directly related to the lecturing style of the lecturers. Instead, it appears to be an individual trait that varies from person to person.

When looking at the quantitative data in content sequences, some differences appear which emphasize the multimodality of structuring segments. Table 3 describes the choices of semiotic resources made by the lecturers in the six short clips in which content is developed. 


\begin{tabular}{|c|c|c|c|c|c|c|c|c|}
\hline \multirow{2}{*}{ System } & \multirow{2}{*}{\multicolumn{2}{|c|}{ System choices }} & \multicolumn{6}{|c|}{ System utilization (\% over total duration) } \\
\hline & & & C1 & $\mathrm{C2}$ & C3 & $\mathrm{C4}$ & C5 & C6 \\
\hline \multirow{6}{*}{$\begin{array}{l}\text { Verbal } \\
\text { mode }\end{array}$} & \multirow{5}{*}{ Metadiscourse } & 1- Introducing topic & - & - & - & - & - & - \\
\hline & & 8- Previewing & - & - & - & - & - & - \\
\hline & & 9- Reviewing & - & - & - & - & - & - \\
\hline & & 10- Contextualizing & - & - & - & - & - & - \\
\hline & & TOTAL & - & - & - & - & - & - \\
\hline & \multicolumn{2}{|l|}{ Pauses } & 30.77 & 12.50 & 14.29 & 20.83 & 13.53 & 23.47 \\
\hline \multirow{5}{*}{ Gestures } & \multicolumn{2}{|l|}{ Total gesturing } & 30.76 & 57.49 & 34.40 & 71.67 & - & 16.32 \\
\hline & \multirow{4}{*}{ Gesture type } & Iconic & - & 3.33 & 6.40 & 7.50 & - & - \\
\hline & & Metaphoric & 0.64 & 15.83 & - & 5 & - & 4.08 \\
\hline & & Deictic & 8.97 & - & 4.80 & - & - & - \\
\hline & & Beat & 21.15 & 38.33 & 23.20 & 59.17 & - & 12.24 \\
\hline \multirow{4}{*}{$\begin{array}{l}\text { Gaze } \\
\text { direction }\end{array}$} & \multicolumn{2}{|c|}{ Towards the audience } & 38.61 & 54.17 & 97.64 & 94.17 & 20.15 & 37.78 \\
\hline & \multicolumn{2}{|c|}{ Towards the notes } & 60.13 & 45 & - & 2.50 & 29.10 & 61.22 \\
\hline & \multicolumn{2}{|c|}{ Towards the book } & - & - & - & 2.50 & - & - \\
\hline & \multicolumn{2}{|l|}{ Other } & 1.26 & 0.83 & 2.36 & 0.83 & 0.75 & 1 \\
\hline \multirow{3}{*}{$\begin{array}{l}\text { Head } \\
\text { movement }\end{array}$} & \multicolumn{2}{|l|}{ Iconic } & - & 0.83 & - & - & - & - \\
\hline & \multirow{2}{*}{ Novel } & Deictic & - & - & - & - & - & - \\
\hline & & Beat & 1.28 & 5 & 18.25 & - & - & 1.02 \\
\hline \multirow{6}{*}{ Posture } & \multirow{4}{*}{ Standing } & Upright & 56.95 & 73.70 & - & 97.50 & 24.63 & 29.29 \\
\hline & & Towards the lectern & 43.05 & 26.30 & - & - & 75.37 & 70.71 \\
\hline & & Towards the table & - & - & - & 2.50 & - & - \\
\hline & & Of which, swaying & 50.60 & 16.44 & - & - & 83.58 & 14.29 \\
\hline & \multirow{2}{*}{$\begin{array}{l}\text { Sitting on the } \\
\text { table }\end{array}$} & Cross-legged & - & - & 84.25 & - & - & - \\
\hline & & Stretched & - & - & 15.75 & - & - & - \\
\hline \multirow{4}{*}{ Proxemics } & \multicolumn{2}{|c|}{ Behind the lectern } & 100 & 100 & - & - & 100 & 100 \\
\hline & \multicolumn{2}{|c|}{ On the table } & - & - & 100 & - & - & - \\
\hline & \multicolumn{2}{|l|}{ By the table } & - & - & - & 2.50 & - & - \\
\hline & \multicolumn{2}{|c|}{ In front of the audience } & - & - & - & 97.50 & - & - \\
\hline \multirow{5}{*}{$\begin{array}{l}\text { Facial } \\
\text { expression }\end{array}$} & \multirow{2}{*}{ Brows } & Eyebrow raising & 1.91 & 4.17 & 13.49 & 2.52 & 0.75 & 10.20 \\
\hline & & Frowning & 0.64 & - & 17.46 & - & - & 7.14 \\
\hline & & Smiling & - & 0.83 & - & - & - & - \\
\hline & Lower face & Lip licking & 2.55 & 0.83 & 0.79 & 1.68 & 6.77 & - \\
\hline & & Swallowing & 1.91 & 1.67 & 0.79 & - & - & - \\
\hline
\end{tabular}

Table 3. Percentage of use of modes in content sequences

The main difference between structuring segments and content sections has to do with the verbal mode. In the dataset selected for the analysis of semiotic resources during content sections, no instances of organizational metadiscourse were found. Moreover, the use of silences is slightly higher in all lecturers except for the lecturer in C5, for whom it is slightly lower. The higher presence of silences may be the result of longer periods of thinking, which contrasts with more spontaneous talk when organizing the message.

As for the use of gestures, slight differences are shown in conversational style lecturers, who use fewer gestures in content sections. Moreover, in reading style 
lecturers, no gestures have been identified in the lecturer of C5, and only a slight higher presence of beats is detected for the lecturer in C6. The differences are higher for rhetorical style lecturers: the lecturer in C3 employs considerably less gestures (34.40\% vs. $50.4 \%$ in structuring segments) and the lecturer in C4 employs considerably more $(71.67 \%$ vs. $56.63 \%)$ as a result of a higher number of beats. All in all, the results of the comparison in the use of gestures seem inconclusive and might suggest a higher co-occurrence of metadiscourse and gestures in C1, C2, C3. This co-occurrence may point towards a will of attracting the audience's attention and emphasizing an organizational message. The use of gestures in structuring segments and in content sections is especially relevant for the lecturer in C3, who employs more gestures during structuring segments. As shown in previous studies (Bernad-Mechó, 2018), structuring segments may serve as a very important organizational tool in rhetorical style lecturers, for whom the general use of metadiscourse is lower and, therefore, there seems to be a need to emphasize the directions of the lecture.

The differences in the use of gaze are straightforward. Both, conversational and reading style lecturers turn their gaze towards their notes more during content sections. This indicates that structuring segments may be performed in a more spontaneous and less note-constrained manner in which gaze is directed to the audience more frequently either for engagement or to signal metadiscursive functions. In the normal lecturing processes, conversational and reading style lecturers depend more on their notes. Very slight differences are encountered in rhetorical style lecturers, who look directly at their audiences for most of the time.

As for the use of head movements, the percentages differing from one analysis to the other are too small to be representative, except in the case of the lecturer in C3. A significantly different use of head movement has been identified between the structuring segment $(0.80 \%)$ and the content sequence $(18.25 \%)$. To explain this abrupt increase, a qualitative exploration is necessary. In this sense, this lecturer uses a series of head movements that coincide with emphatic intonation as the lecturer makes a point on one of his arguments. With this background, it would be fair to assume that these differences are the result of an idiosyncratic trait of the speaker and the specific emphasis he is placing on a particular explanation, rather than a trait of the sections of the lecture per se.

Changes in posture are particularly relevant for reading style lecturers who now devote a higher percentage of the time to leaning towards the lectern $175.37 \%$ during content sequences vs. 50\% in structuring segments for the lecturer in C5; and 70.71 vs. 65.69 for the lecturer in C6) . Once again, this indicates a higher relevance of the role of the notes for this type of lecturers as spontaneous sections are less frequent during content sections. As for swaying, slight variations are found: the lecturer in C6 sways slightly less, which may reflect longer periods of note-checking; while the one in C5 sways slightly more, which indicates a more steady rhythm to deliver the lecture. 
The use of proxemics is almost the same in both datasets with no relevant changes. Finally, in the use of facial expression, we may conclude that the slight differences coincide with the emphasis of certain sections of the discourse. In particular, lecturers in C3 and C6 show a higher percentage of eyebrow raising which co-occurs with an emphasis of the content.

All things considered, some differences are found in the use of semiotic resources in structuring segments and in content sequences from a quantitative perspective. These distinctions occur mainly in the use of gestures, gaze and posture. In general terms, these modes become less relevant in content sequences, which seems to indicate that structuring segments are more modally dense and therefore, highly reinforced through non-verbal language. In turn, elements like head movements and facial expressions gain more importance in content sections, and thus make up for the decrease of other embodied modes. We might argue that these modes may afford less interaction than gestures or gaze, as they do not necessarily act as backchannelling requests prompting a response from the audience. Still, they seem to play a role in their respective multimodal ensembles working as boosters when the availability of other embodied modes is limited, i.e. when lecturers read from their notes or lean on the lectern. Furthermore, these modes may also be employed as rhythm markers within content sequences. Be that as it may, and although the quantitative results point towards a pattern in the use of semiotic resources, no clear-cut claims can be made due to the limited data available. In this sense, the qualitative exploration of the multimodal ensembles in these sections provided below may clarify some of the specific uses of modes.

\subsection{A qualitative analysis of common multimodal ensembles}

As seen in the previous section, both structuring segments and content sequences are carried out through a multiplicity of modes that co-occur in the conveyance of meaning. The modal density of the discourse, i.e. the number and relevance of cooccurring modes seems to be greater in structuring segments, as organizational metadiscourse is most often co-expressed with non-verbal resources, which contributes to highlighting the connections across the contents, and engaging the audience. All in all, the modal density in structuring segments appears to have the communicative function of reinforcing the organizational message and connecting with the listeners. In these segments, lecturers try to recapture the attention of the audience and carefully explain to them where they are, where they come from and where they are going in terms of content. Content sequences, on the contrary, are less modally dense and most co-occurrences of the verbal mode with other modes seem to serve as rhythm markers (for instance, through the use of beat gestures or by swaying), or to carefully reinforce certain parts of the discourse. In order to clarify these claims let us take a look at a representative example of a multimodal ensemble from each of the sections under review: structuring segments and content sequences. 
Figure 3 displays a fragment of structuring segment C5_L15_SS in which a reading style lecturer introduces a topic. In this fragment, the lecturer turns his gaze away from his notes to directly address the audience in a spontaneous manner (images 1 and 2). This fragment includes the only gesture performed by this lecturer in the whole structuring segment considered for these analyses. The lecturer verbally introduces the topic ("and today what I'd like to do is to look at a subset of the bigger problem [...] tropical medicine") and performs an iconic gesture by placing his thumb and index parallel to each other as a non-verbal counterpart of "subset". This iconic gesture is used to visually represent the "subset" that the lecturer is talking about, thus reinforcing this metadiscursive description of the structure of the contents. Moreover, the spontaneous introduction of the topic is separated from the following reading section by a pause and a swallowing (image 3 ). These spontaneous ensembles tend to be more modally complex than those in reading sections (content sequences) in an effort to engage the audience multimodally in the introduction of a new topic. In short, this lecturer moves from a content sequence in which he is focused on the notes to a structuring segment by directly addressing the audience and offering a much more complex multimodal ensemble.

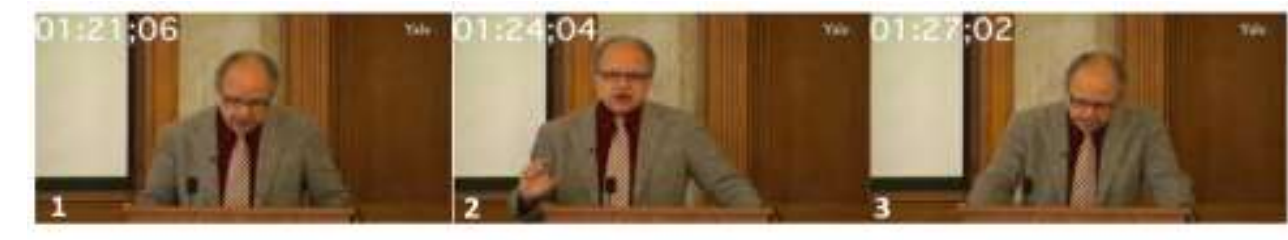

and today what I'd like to do is to look at a subset of the bigger problem
\begin{tabular}{|l|l|}
\hline METADISCOURSE & Introducing topic \\
\hline GESTURE (TYPE) & Iconic \\
\hline GAZE & To the audience \\
\hline HEAD MOVEMENT (TYPE) & None \\
\hline POSTURE & Upright \\
\hline PROXEMICS & Behind the lectern \\
\hline FACIAL EXPRESSION & None \\
\hline
\end{tabular}

Figure 3. Dense multimodal ensemble in a structuring segment

An example of a multimodal ensemble in content sequences is shown in Figure 4. In this short excerpt, the lecturer in C3 is refuting Freud's argument of the impossibility of imagining one's own death during a content sequence, i.e. he is developing content. He does so mainly through the verbal mode, which contains no organizational metadiscourse. As a rhetorical lecturer, he is not using any sort of notes so he is mainly focused on the audience (gaze and posture facing the audience). Nevertheless, during this section, no gestures are performed. In fact, both of the 
lecturer's hands are placed on the table (image 1). Instead, this section is characterized by a series of modal choices that contribute to marking the rhythm of the interaction. For example, some head beats are performed at the beginning of the utterance and cooccurring with "you know, there's that room in the mind, in your mind's eye..." (image 1). Furthermore, a slight swaying movement of the lecturer to his right and left (images 2 and 3 ) is performed as he speaks. Finally, although the modal density of the fragment is low, some emphasis still seems to be placed on the lecturer's explanation. This is mainly realized through an eyebrow raising instance (image 3) that co-occurs with the phrase "your mind's eye...". This change in the lecturer's facial expression seems to be the result of a self-correction ("in the mind" vs. "in your mind's eye"), and, therefore, some emphasis is placed on the correct expression.

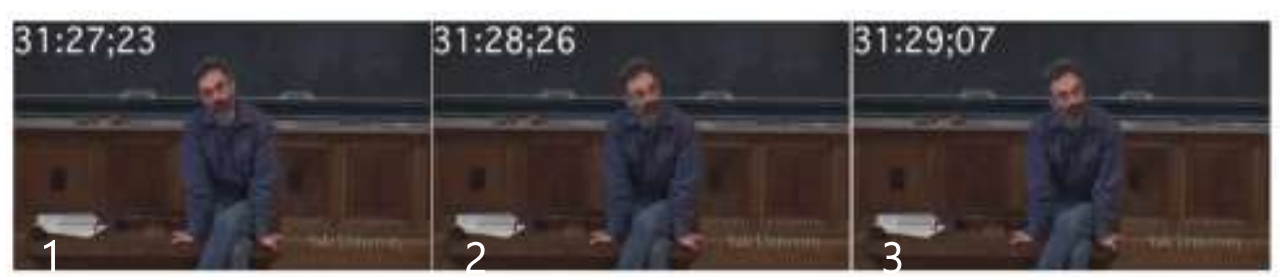

you know, there's that room in the mind, in your mind's eye... you've got a little picture of people sitting around the table

\begin{tabular}{|l|l|}
\hline METADISCOURSE & None (Content) \\
\hline GESTURE (TYPE) & None \\
\hline GAZE & To the audience \\
\hline HEAD MOVEMENT (TYPE) & Novel (Beat) \\
\hline POSTURE & $\begin{array}{l}\text { Sitting cross-legged, moving to one side } \\
\text { and the other }\end{array}$ \\
\hline PROXEMICS & On the table, facing the audience \\
\hline FACIAL EXPRESSION & Eyebrow raising \\
\hline
\end{tabular}

Figure 4. Multimodal ensemble in a content sequence

All in all, the comparison of multimodal ensembles shows two main trends corresponding to each of the communicative events analyzed. On the one hand, structuring segments are modally dense and constitute, many times, an explicit effort to engage the audience and guide them through the lecture. On the other hand, content sequences are less modally dense. Although emphasis still occurs, such emphasis is less marked (for instance, through head movements or facial expression) and some modality seems to be used as rhythm marker. 


\section{CONCLUSIONS}

This paper has explored the modal density of two main sections within monological lectures: structuring segments and content sequences. The initial hypothesis claimed that structuring segments were more modally dense, as lecturers seem to put more emphasis on structural messages that help build the internal architecture of lectures. This hypothesis has been confirmed through quantitative and qualitative data.

On the one hand, the quantitative analyses have shown the percentages of use of a series of semiotic resources in both sections. The results indicate a slightly higher use of semiotic resources (particularly, more gestures, gaze directed to the audience and posture shifts) in structuring segments. Moreover, this points towards the fact that organizational messages are co-expressed both verbally and nonverbally and as well as to their spontaneity. Minor discrepancies in the general trends may be the result of specific idiosyncratic traits of the lecturers.

These quantitative results are confirmed with qualitative data. The exploration of specific multimodal ensembles in structuring segments and content sequences has shown that structuring segments are generally more complex, i.e. modally dense, in terms of co-occurrence of modes. In contrast, the use of multiple modes in content sequences responds to an effort to mark the rhythm of explanations and reinforce specific messages.

Finally, some differences in the use of modes across lecturing styles have also been found, in line with previous research on the matter (see, for instance, BernadMechó \& Fortanet-Gómez, 2019). In this sense, reading style lecturers show a more marked change when moving from content sequences to structuring segments, in which an extra effort is made to engage the audience.

The outcomes of this study have some pedagogical implications, especially within the realm of teacher training in higher education. In short, this study shows that structuring segments are relevant sections in which lecturers focus on capturing the audience's attention. To do so, they offer modally complex structures that divert from the more simple and rhythmical ones when they develop curricular content. By introducing this idea in teacher training programs, a special perspective could be added on the organization of lectures. Furthermore, this article also contributes to raising awareness of the importance of multimodality within academic lectures.

Lastly, as in any empirical research, some limitations may be found. In particular, we could highlight the size of the dataset. Multimodal analyses require smaller corpora to make them time-wise viable. In this regard, these results could be further confirmed or refuted by looking at a larger dataset with more lecturers. Still and all, the results shown in this paper point to a clear tendency that helps define both main moves of monological lectures. 


\section{Acknowledgments}

This study is encompassed within a research project funded by the Ministerio de Ciencia, Innovación y Universidades, Spain (Ref: PGC2018-094823-B-I00) and entitled Análisis de los géneros académicos en la docencia en inglés de grados internacionales desde una perspectiva multimodal y multicanal.

\section{References}

Ädel, A. (2010). Just to give you kind of a map of where we are going: A taxonomy of metadiscourse in spoken and written academic English. Nordic Journal of English Studies, 9(2), 69-97. http://doi.org/10.35360/njes.218

Andric, M., \& Small, S. L. (2012). Gesture's neural language. Frontiers in Psychology, 3. https://doi.org/10.3389/fpsyg.2012.00099

Bernad-Mechó, E. (2018). A multimodal approach to metadiscourse as an organizational tool in lectures (Unpublished doctoral dissertation). Universitat Jaume I, Castelló de la Plana, Spain. http://dx.doi.org/10.6035/14110.2018.189457

Bernad-Mechó, E., \& Fortanet-Gómez, I. (2019). Organizational metadiscourse across lecturing styles: Engagement beyond language. In C. Sancho-Guinda (Ed.), Engagement in professional genres: Deference and disclosure (pp. 321-340). John Benjamins. https://doi.org/10.1075/pbns.301.17ber

Bruti, S. (2015). Teaching learners how to use pragmatic routines through audiovisual material. In B. Crawford Camiciottoli, \& I. Fortanet-Gómez (Eds.), Multimodal analysis in academic settings: From research to teaching (pp. 213-238). Routledge. https://doi.org/10.4324/9781315738758

Chafe, W. (1992). Discourse: An overview. In W. Bright (Ed.), International encyclopedia of linguistics (pp. 356-358). Oxford University Press.

Crawford Camiciottoli, B. (2007). The language of business studies lectures. A corpus-assisted analysis. John Benjamins. https://doi.org/10.1075/pbns.157

Crawford Camiciottoli, B. (2015). Elaborating explanations during OpenCourseWare humanities lectures: The interplay of verbal and nonverbal strategies. In B. Crawford Camiciottoli, \& I. Fortanet-Gómez (Eds.), Multimodal analysis in academic settings: From research to teaching (pp. 144-170). Routledge. https://doi.org/10.4324/9781315738758

Crawford Camiciottoli, B. (2016). A multimodal analysis of interaction in academic lectures: A case study. In V. Bonsignori, \& B. Crawford Camiciottoli (Eds.), Multimodality across communicative settings, discourse domains and genres (pp. 65-92). Cambridge Scholars Publishing.

Dudley-Evans, T. (1994). Variations in the discourse patterns favoured by different disciplines and their pedagogical implications. In J. Flowerdew (Ed.), Academic listening: Research perspectives (pp. 146-158). Cambridge University Press. https://doi.org/10.1017/CB09781139524612.012

Flowerdew, J. (1994). Academic listening: Research perspectives. Cambridge University Press. https://doi.org/10.1017/CB09781139524612

Fortanet-Gómez, I. (2005). Honoris Causa speeches: An approach to structure. Discourse Studies, 7(1), 31-51. https://doi.org/10.1177/1461445605048766

Fortanet-Gómez, I., \& Bellés Fortuño, B. (2005). Spoken academic discourse: An approach to research on lectures. Volumen Monográfico, 2005, 161-178. 
Kress, G. (2010). Multimodality: A social semiotic approach to contemporary communication. Routledge.

Leonard, T., \& Cummins, F.(2011). The temporal relation between beat gestures and speech. Language and Cognitive Processes, 26(10),1457-1471. https://doi.org/10.1080/01690965.2010.500218

Lynch, T. (1994). Training lectures for international audiences. In J. Flowerdew (Ed.), Academic listening: Research perspectives (pp. 269-289). Cambridge University Press. https://doi.org/10.1017/CB09781139524612.020

MacDonald, M., Badger, R., \& White, G. (2000). The real thing?: Authenticity and academic listening. English for Specific Purposes, 19(3), 253-267. https://doi.org/10.1016/S0889-4906(98)00028-3

Malavska, V. (2016). Genre of an academic lecture. LLCE, 3(2), 56-84. https://doi.org/10.1515/llce-2016-0010

McNeill, D. (1992). Hand and mind: What gestures reveal about thought. The University of Chicago Press. Norris, S. (2004). Analyzing multimodal interaction: A methodological framework. Routledge. https://doi.org/10.4324/9780203379493

O’Halloran, K. L., Podlasov, A., Chua, A., \& E, M. K. L. (2012). Interactive software for multimodal analysis. Visual Communication, 11(3), 363-381. https://doi.org/10.1177/1470357212446414

Tan, S., O'Halloran, K. L., \& Wignell, P. (2016). Multimodal research: Addressing the complexity of multimodal environments and the challenges for CALL. ReCALL, 28(3), 253-273. https://doi.org/10.1017/S0958344016000124

Thompson, J. (1992). The concept of culture. Polity Press.

Thompson, S. (1994). Frameworks and contexts: A genre-based approach to analysing lecture introductions. English for Specific Purposes, 13(2), 171-187. https://doi.org/10.1016/0889-4906(94)90014-0

Waugh, G. H., \& Waugh, R. F. (1999). The new technologies versus the lecture tradition in higher education: Is change possible? Australian Journal of Teacher Education, 24(1), 35-51. https://doi.org/10.14221/ajte.1999v24n1.3

EDGAR BERNAD-MECHó is Assistant Professor at Universitat Jaume I, Spain. Within the Group for Research on Academic and Professional English (GRAPE), he studies the use of metadiscourse and multimodality in higher education as well as the language used in science dissemination. His latest publications include a methodological article on approaches towards the multimodal analysis of lectures in Atlantis (Q1); the co-edition of a special issue of Ibérica (Q2) on multimodality; and a co-authored chapter in John Benjamins. In addition, he is the author of an edited volume on multimodality and Integrating Content and Language in Higher Education (ICLHE), which has already been accepted for publication in Routledge. 